\title{
SENTIDOS DAS PRÁTICAS AVALIATIVAS NA SALA DE AULA DE ESPANHOL COMO LÍNGUA ADICIONAL NO COTIDIANO ESCOLAR DO ALUNO SURDO
}

\author{
Eliane Elenice JORGE \\ Universidade Federal de Santa Catarina \\ elianeelenice@gmail.com
}

Resumo: Esse artigo tem como objetivo principal apresentar uma pesquisa de mestrado que busca problematizar a prática avaliativa de espanhol como língua adicional para alunos surdos. A finalidade principal desse estudo é identificar, descrever, analisar e interpretar rotinas do trabalho pedagógico na sala de aula de espanhol, focando nas práticas avaliativas e no modo como alunos surdos interagem com essas práticas em seu cotidiano escolar. Além disso, aponta para discussões que possam contribuir com 0 processo de ensino/aprendizagem do espanhol desse alunado. A pesquisa, desenvolvida a partir de uma perspectiva etnográfica, interpretativista, consiste de registro de dados através da observação sistemática das aulas de espanhol, no contexto de um sexto ano do ensino fundamental de uma escola pública da rede básica de ensino. O grupo composto de dezoito alunos, onze ouvintes e sete surdos, conta com uma professora que domina três idiomas: português, espanhol e LIBRAS. O referencial teórico que norteia este trabalho nos conduz a repensar a prática avaliativa do ensino da língua adicional sob uma perspectiva póscolonialista (MOITA LOPES, 1996, 2006; SCARAMUCCI, 2000; RAJAGOPALAN, 2003; PENNYCOOK, 2007; SCHLATTER e GARCEZ, 2009; LUCENA, 2006, 2012, entre outros). Sob um ponto de vista êmico, mostraremos nessa apresentação algumas das rotinas pedagógicas dos alunos surdos, especialmente aquelas voltadas para práticas avaliativas. Os dados revelam que apesar do empenho de professores e intérprete no processo de ensino/aprendizagem e inclusão dos alunos surdos na aula de espanholas avaliações realizadas não são significativas e tampouco se mostram produtivas, contribuindo pouco com a aprendizagem desses alunos.

Palavras-chave: Ensino de espanhol. Surdez. Avaliação.

Abstract: The main objective of this paper is to present a master's research that seeks to problematize the assessment practice of Spanish as an additional language for deaf students. The main purpose of this study is to identify, describe, analyze and interpret routine pedagogical work in Spanish classrooms, focusing on the assessment practices and on how deaf students interact with these practices on their daily school routine. Besides, it points out to discussions that can contribute to the Spanish teaching/learning process of these students. The research, developed from an ethnographic, interpretative perspective, consists of data register through systematic observation of Spanish classes in the context of a sixth grade class in a public school from the basic education level. The group consists of eighteen students, eleven hearing and seven deaf ones, and a teacher who speaks three idioms: Portuguese, Spanish and LIBRAS. The theoretical framework that guides this work leads us to rethink 
the assessment practice of teaching an additional language in a post-colonial perspective (MOITA LOPES, 1996, 2006; SCARAMUCCI, 2000; RAJAGOPALAN, 2003; PENNYCOOK, 2007; SCHLATTER \& GARCEZ, 2009; LUCENA, 2006, 2012, and others.). Under an emic point of view, this paper will show some of the routines of teaching deaf students, especially those related to assessment practices. The data show that, despite the commitment of teachers and interpreter in the teaching / learning process and inclusion of deaf students in Spanish class, most evaluations are not significant, nor productive, contributing poorly to the learning of these students.

Key words: Spanish teaching. Deafness. Assessment.

\section{Introdução}

Há décadas pesquisadores de várias áreas buscam por aquelas que seriam as formas adequadas de ensinar e aprender uma língua estrangeira, porém esta é uma questão de difícil solução e discussões inesgotáveis. Com o surgimento da Linguística Aplicada, os olhares se voltam para as relações sociais e tudo o que isso acarreta para o ensino/aprendizagem de Língua Estrangeira. O ensino de línguas não está mais centrado puramente na aprendizagem da estrutura linguística, indo muito além disso, uma vez que, contemporaneamente, se consideram de modo muito mais contundente, aspectos sociais, culturais e políticos que permeiam o aprendizado de um idioma. Pensando a língua(gem) como prática social com a qual fazemos coisas no mundo (SCHLATTER e GARCEZ, 2009). Fazer uso de um idioma perpassa o domínio das quatro habilidades (ouvir, falar, ler e escrever). Não há como se pensar língua sem considerar os participantes do evento comunicativo e os significados que se constroem nesse processo. Ensinar uma língua adicional não pode mais centrar-se na busca por um falante-nativo ideal e tampouco, se pode ainda acreditar que aprender um idioma reserva-se a reconhecer a língua e a cultura do outro, como um objeto a ser contemplado e aceito, sem considerar as relações de poder existentes quando culturas se deparam (COX e ASSIS-PETERSON, 1999). Sendo assim, justifica-se pensar uma pedagogia que vise ir além do aprendizado de línguas para o acesso ao mundo, ao outro e sua cultura, pois é na e através da linguagem que ocorrem as disputas de poder, a hibridização do conhecimento e a transformação social.

Pensares em Revista, São Gonçalo-RJ, n.2, p. 109 - 135, jan./jun. 2013 
Então, necessitamos de uma proposta pedagógica que proporcione a mudança do ensino de línguas e que busque a transformação da sociedade. Isso é o que se pretende com a pedagogia crítica. Segundo Clemente (2009) a pedagogia crítica pode ser definida como o enfoque educativo que dá conta de como as relações sociais, culturais e políticas se vinculam na sala de aula, evidenciando a maneira como o poder pode circular em diferentes níveis.

Sob esta perspectiva não existe um detentor do saber, uma única verdade ou um método absoluto para a aprendizagem de língua estrangeira. Nesse caso, entende-se que o que acontece na sala de aula é a hibridização de conhecimentos advinda do processo de construção da vida social, onde os sujeitos, historicamente situados, são os agentes de seus saberes (FREIRE, 2011). Portanto, interessa-nos pensar a inclusão das diversas identidades existentes dentro da sala de aula de língua adicional, inclusive daqueles denominados pela educação inclusiva como alunos com necessidades educacionais especiais, representados neste trabalho pelos alunos surdos, foco desta pesquisa dentro dos princípios da pedagogia crítica.

O motivo que me levou a pesquisar este tema se deve a atual realidade da escola na qual leciono aulas de espanhol como língua estrangeira/ adicional (LE/LA), o Colégio de Aplicação da Universidade Federal de Santa Catarina (CA/UFSC). Com a aplicação da Lei de Diretrizes e Bases de Educação Brasileira no. 9.394, de 20 de dezembro de 1996, que garante aos educandos com histórico de deficiência a educação na rede regular de ensino, o CA/UFSC recebe um número crescente destes estudantes com diagnóstico variado: paralisia cerebral (PC), síndrome de Down, cegueira, surdez, autismo, entre outros.

Constatei que com a inclusão desses alunos chegaram também as angústias do corpo docente sobre o que fazer, como lidar com a diferença, como ensinar esses alunos dadas as condições diferenciadas da maioria e, especialmente, as dúvidas que surgiam sobre como avaliar alguém com necessidades tão específicas. Essas e outras questões fizeram com que eu buscasse mais informações sobre a educação especial e a inclusão social, sobretudo após o contato pela primeira vez, em 2005, com um aluno surdo na aula de espanhol como LE/LA, que me fez vivenciar todas as angustias citadas acima. As dificuldades encontradas no processo de ensino/aprendizagem e 0 
desejo de encontrar metodologias e avaliações adequadas ao contexto da surdez levaram-me a desenvolver a pesquisa da qual apresento uma pequena mostra neste artigo.

Para desenvolver este trabalho, conto com um aporte teórico que apresenta estudos que tratam sobre a educação de surdos e a dicotomia da educação inclusiva e educação bilíngue (SKLIAR, 2001; MACHADO, 2008; GRANNIER, 2007; GESSER, 2006, entre outros). Apresento os conceitos de interculturalidade e bi/plurilinguismo (MAHER, 2007; MOURA; 2009, GARCIA, 2009; entre outros) que são peças chaves para entender o contexto da sala de aula brasileira. E, na busca para entender como os alunos surdos lidam com a prática avaliativa em sala de língua adicional, em um contexto onde a língua dominante não é sua primeira língua, me valho das ideias de Zabala (1998); Scaramucci (2000); Lucena (2011); Catane e Gallego (2009); Schlatter et. al.(2005), entre outros.

\section{A educação de surdos inclusiva versus educação bilíngue no contexto da escola regular}

A ideia de educação inclusiva surge nos Estados Unidos, no ano de 1975, através da lei pública 94.142, mas foi com a Declaração de Salamanca, em junho de 1994, que os países envolvidos assumiram "a educação para todos", dando origem ao termo "Educação Inclusiva". Também conhecida como Educação Especial, a educação inclusiva trata da integração de portadores de necessidades especiais no sistema de ensino regular e é uma diretriz constitucional presente na política governamental há quase dez anos. No contexto específico da surdez, a perspectiva clínica sobre o assunto fez como que os órgãos governamentais identificassem os surdos como portadores de deficiência, sem que levasse em conta a visão sócio-antropológica da surdez que define o surdo como um ser sócio-historicamente constituído. Portanto, a questão da surdez não pode ser tratada simplesmente como uma patologia, porém de acordo com Machado (2008) a abordagem clínico-terapêutica ainda está presente na educação especial, da qual faz parte a educação de surdos e esta ainda busca a 'recuperação' do surdo, visando sua integração na sociedade dominante.

Pensares em Revista, São Gonçalo-RJ, n.2, p. 109 - 135, jan./jun. 2013 
Skliar (2001) define a educação especial como:

[...] um subproduto da educação, cujos componentes ideológicos, políticos, teóricos, etc. são, no geral, de natureza discriminatória, descontínua e anacrônica, conduzindo a uma prática permanente de exclusão e inclusão. [...] ela é o espaço habitual onde se produzem e se reproduzem táticas e estratégias de naturalização dos surdos em ouvintes, é o local onde a surdez é disfarçada. (SKLIAR, 2001, p.11)

Concordando com este conceito muitos estudiosos, assim como Skliar, acreditam que a educação do aluno surdo não pode estar centrada na Educação Especial, neste caso a surdez deve ser pensada por outro prisma, através do qual deve ser discutido um sistema de educação para os surdos onde se respeite suas diferenças, sua identidade, sua cultura e seu idioma: a língua de sinais brasileira. Até pouco tempo atrás a educação para os surdos vinha sendo pensada e efetivada somente pelos ouvintes. Para que a educação dos surdos possa ser pensada pelos e com os surdos, o primeiro passo é aceitar a surdez como diferença política e os surdos como grupo social, com história, linguagem e identidade próprias. Assim podemos pensar a educação para surdos fora do contexto da educação dita "especial", destinada a um grupo de sujeitos indiscriminadamente relacionados, onde cegos, surdos e deficientes mentais estão em um mesmo patamar. Segundo Grannier (2007):

A Sociolinguística e a Linguística Aplicada ao ensino de línguas, visando à integração de minorias linguísticas, têm proposto que, para as situações em que uma criança desconhece a língua utilizada na escola, sejam adotados programas de educação bilíngue, a fim de possibilitar uma comunicação plena, desde 0 início, entre professor e aluno, na primeira língua da criança, assegurando-lhe o acesso aos conteúdos escolares. (GRANNIER, 2007, p. 202)

Sobre a proposta exposta acima gostaria de dizer que confio na possibilidade do reconhecimento dos surdos como parte das minorias linguísticas deste país e na sua inclusão de fato no contexto escolar nacional, porém é importante ressaltar que outras questões sociais estão envolvidas e que um programa bilíngue é apenas parte de uma alternativa para amenizar as dificuldades de nossos alunos surdos. Dentro do contexto escolar brasileiro, além da diversidade de graus de surdez existentes, há uma infinidade de questões que acompanham este alunado em sua trajetória. Dentre elas 
podemos citar o fato de que muitos dos alunos surdos que ingressam na escola não dominam a LIBRAS, idioma através do qual têm o direito de receber sua formação educacional. Em muitos casos, vistos pela família como incapazes, esses alunos não foram incentivados a comunicar-se e, sendo assim, ficam limitados as línguas de sinais caseiras ou familiares (GESSER, 2009). É na escola, para muitos deles, a primeira vez, que são reconhecidos como cidadãos e aprendem a comunicar-se na forma padrão da LIBRAS.

Outro fato é que o aprendizado de $1^{\underline{a}}$ e $2^{\underline{a}}$ línguas não é garantia de acesso aos conteúdos escolares. Muitos são os aspectos para que isso ocorra ou não. E isto vale não só para os surdos, mas para todo e qualquer ser humano em fase escolar. Além disso, o acesso das comunidades minoritarizadas' à educação ainda está preso ao papel, não nos permitindo vislumbrá-lo no espaço da sala de aula de modo efetivo. A inclusão se dá de uma maneira muito frágil, limitando-se mais a ocupação de um espaço físico do que a conquista de seu lugar na sociedade. Isso não quer dizer que a educação inclusiva, não possa também colaborar para o desenvolvimento do aluno surdo, como vislumbra a educação bilíngue. Segundo Perlin e Quadros (1997) a educação de surdos deve acontecer na escola regular com a utilização da língua de sinais para disseminar o conhecimento, porém as autoras alegam que "as escolas inclusivas não apresentam as condições básicas para o desenvolvimento das relações linguísticas, sociais, culturais e políticas da comunidade surda". O direito de receber instrução em sua língua natural muitas vezes não é respeitado e na maioria das vezes a LIBRAS é apenas usada como meio para a aprendizagem da língua oral representação da cultura dominante (SÁ, 1999).

De acordo com Moura (2009), no que diz respeito à formação dos professores que trabalham na rede básica de ensino, são poucos os que se sentem preparados para trabalhar no contexto da inclusão dos ditos 'alunos especiais'. A LDB em seu capítulo V, art. 58, garante "serviço de apoio especializado, na escola regular, para atender às peculiaridades da clientela de educação especial", porém esses serviços somente chegam à escola depois de uma longa luta da administração da instituição e dos familiares envolvidos. Os cursos de capacitação para os professores do ensino regular, que visam à integração dos educandos nas classes comuns, têm sido considerados até o 
momento escassos, atendendo apenas uma pequena parte do corpo docente. Assim, continuamos nós, professores, com as angústias e dificuldades do processo de inclusão, caminhando a passos lentos, buscando também incluirnos nessa nova empreitada, que é dar ao aluno surdo e a todos aqueles classificados pela lei de diretrizes e bases da educação como portadores de necessidades educacionais especiais, as condições necessárias que the garantam o pleno desenvolvimento e exercício da cidadania.

Outra questão delicada quando falamos de inclusão é a aceitação pela comunidade escolar, do outro, do diferente. E esse é um tema que transcende os limites do ambiente educacional, é um problema da sociedade em que vivemos, onde os grupos minoritarizados são sempre vistos como inferiores e a anormalidade tem caráter negativo. Esse caráter foi se naturalizando na sociedade de tal modo que 'necessidades especiais' passaram a ser caracterizadas, de modo generalizado, como deficiência, não se levando em consideração características sociais, linguísticas, culturais e políticas que definem esses grupos (SKLIAR, 2001; QUADROS, 2006; MACHADO, 2008).

Então, como já citado anteriormente ainda são inúmeros os percalços para uma educação de qualidade a toda a comunidade surda brasileira, tanto na perspectiva da educação bilíngue como da educação inclusiva. Por mais que se tenha avançado em relação às políticas públicas que legitimam o uso da LIBRAS, que garantem a presença de intérprete em sala de aula regular, que defendem a aplicação de avaliações diferenciadas, entre outras ações, ainda existem contextos em que essas diretrizes não se aplicam ou são desenvolvidas de uma maneira muito precária, o que resulta no fracasso escolar do aluno surdo. Na visão de Skliar (2001), existem três tipos de justificativas impróprias para esse fracasso. Primeiramente, é atribuída ao próprio indivíduo a culpa de seu fracasso. Fracasso então reservado a sua condição de surdo. Em segundo lugar, o fracasso é atribuído aos professores ouvintes. A formação inadequada, o desconhecimento da LIBRAS e do significado da surdez são aspectos que fazem com que eles sejam considerados também responsáveis pelo insucesso do aluno surdo. $E$, em terceiro lugar, encontra-se o método de ensino. Segundo o autor em nenhuma das justificativas mencionadas se denuncia o "fracasso da instituição-escola, das políticas educacionais e da responsabilidade do Estado" (SKLIAR, 2001, 
p.18). Para ele, o fracasso da educação dos surdos está na representação ouvintista de tudo que se relaciona com o universo da surdez: o significado ouvintista do que é ser surdo, os direitos linguísticos e de cidadania, a definição de teorias de aprendizagem, o conhecimento do professor ouvinte sobre o indivíduo surdo como sujeito constituído sócio-historicamente, etc. Segundo o autor, na verdade, a educação dos surdos não fracassou, "ela apenas conseguiu os resultados previstos em função dos mecanismos e das relações de poderes e de saberes atuais" (SKLIAR, op. cit., p.19).

Vivemos em pleno século XXI com a máxima: "educação para todos", presente em todos os discursos e documentos oficiais de nosso país, porém entre os muros da escola, no contexto que está além do discurso, importa perguntar 'de quem' é essa educação e quem são esses 'todos' que serão contemplados por essa política. Segundo Sá (2006), "participar de um processo educativo significativo é o que deveria implicar o propalado "direito de todos" (SÁ, 1997, p. 34)." Definimos como processo significativo aquele que, como coloca Lucena (2012), dê voz aos envolvidos no processo, que permita a sobreposição do contexto micro sobre o macro, que respeite "os aspectos discursivos e sócio-culturais, políticos e ideológicos locais" (LUCENA, 2012, p.124).

\section{Plurilinguismo, educação intercultural e a língua adicional na sala de aula inclusiva}

O 'plurilinguismo' diferente do 'multilinguismo', que se caracteriza basicamente pelo conhecimento de certo número de línguas ou a existência de vários idiomas em um país, vai além desta perspectiva, sendo entendido como a apropriação pelo indivíduo de uma pluralidade de idiomas que passam a fazer parte de sua comunicação em seu contexto social. De acordo com o Quadro Europeu comum de referência para as línguas (2001), a abordagem plurilinguística:

[...] acentua o facto de que, à medida que a experiência pessoal de um indivíduo no contexto cultural se expande, da língua falada em casa para a da sociedade em geral e, depois, para as línguas de outros povos (aprendidas na escola, na universidade ou por experiência directa), essas línguas e culturas não ficam

Pensares em Revista, São Gonçalo-RJ, n.2, p. 109 - 135, jan./jun. 2013 
armazenadas em compartimentos mentais rigorosamente separados; pelo contrário, constrói-se uma competência comunicativa, para a qual contribuem todo conhecimento e toda a experiência das línguas e na qual as línguas se inter-relacionam e interagem. (PORTUGAL, 2000, p. 23)

Se levarmos em consideração os aspectos do plurilinguismo, não faz sentido continuar pensando o ensino da língua dita 'estrangeira', muito menos almejar com este ensino a busca de um 'falante-nativo ideal', terminologia esta que não faz nenhum sentido dentro da corrente da pedagogia crítica e do plurilinguismo. Nesta perspectiva a língua sofre uma modificação de seu caráter 'estrangeiro'. A partir do momento que nos apropriamos da língua do outro, ela já não nos é estranha, faz parte de nosso repertório linguístico, podendo ser considerada como uma língua adicional (SCHLATTER e GARCEZ, 2009).

Pensemos, como exemplo, no ensino da língua adicional, em turma inclusiva, com alunos surdos e ouvintes, onde consequentemente há o processo de hibridização de três idiomas, ou até mais, se considerarmos as variações dos idiomas aí imbricados. Além de uma diversidade cultural maior do que podemos imaginar se pensarmos nos grupos minoritários, nos quais cada aluno pode estar inserido (negros, homossexuais, surdos, índios, etc.), cada indivíduo é uma história a ser vivida, uma diferença a ser respeitada, uma voz a ser ouvida, com competência para interagir linguística e culturalmente em diversos contextos linguísticos. A função da escola é mostrar-lhes os caminhos para que isso aconteça e para tal desafio é preciso estar preparada. Para Bizarro e Braga (2004):

a educação intercultural consolida-se quando o professor propicia a igualdade de oportunidades de todos os grupos presentes na escola e o respeito pela pluralidade, num plano democrático de tomada de decisões e de gestão de espaços de diálogo e de comunicação entre todos (BIZZARRO e BRAGA, 2004, p.58).

Porém, cabe ressaltar que esta não é uma tarefa só do professor, já que como citaram as autoras, trata-se, antes de mais nada, de uma questão de política educacional. Para que tal propósito político chegue até a sala de aula é necessário a criação de um currículo que garanta a voz das minorias e maiorias minoritarizadas, além de uma política de formação de professores que

Pensares em Revista, São Gonçalo-RJ, n.2, p. 109 - 135, jan./jun. 2013 
contemple esta lacuna, já que a realidade que encontramos nas escolas brasileiras está longe de refletir os ideais de uma 'educação intercultural' plurilíngue. Para se trabalhar nesta perspectiva é necessário que o professor saiba identificar e distinguir os conceitos de atitudes, valores, crenças e comportamentos, e não permitir que estereótipos se sobressaiam no seu espaço. "Trabalhando nesse sentido, o educador contribui para que o aluno conheça a si próprio e ao outro, ou seja, busque o outro que existe em si" (MIRANDA, 2001, p.42). Ser um "agente de ensino, pensante, atuante, mediador cultural por excelência" (op.cit., p.43), pode não ser utopia, mas é uma árdua tarefa em uma sociedade que preza pela hegemonia da cultura dominante.

Penso que um dos princípios para o ensino de línguas em turma inclusiva é primeiramente respeitar as diversas identidades que aí se encontram. Digo respeitar não no sentido de tolerar, mas respeitar no sentido de valorizar a diversidade cultural presente em sala de aula, desafiando os preconceitos e estereótipos tão arraigados em nossa sociedade. Outra questão a se pensar é a adequação de métodos e estratégias que possibilitem o aprendizado dessa diversidade. Quando falo em métodos e estratégias não me refiro a nenhuma cartilha ou manual que indique todos os passos para um ensino efetivo de um idioma, falo do processo de construção, de troca de conhecimento, de ouvir o aluno, sua história, sua crença e dar voz àqueles que sempre estiveram à margem do sistema, classificados como deficientes, com necessidade de normalização ou adequação a sociedade. Segundo Canen (2002) a linguagem tem grande importância na formação das identidades plurais. A linguagem faz parte da identidade do indivíduo, e "é uma síntese cultural que emerge a partir de sua história familiar, inserção econômica, social, cultural e assim por diante" (CANEN, 2002, p.60). Segundo a autora, quando não respeitamos a linguagem de qualquer que seja o indivíduo que compõe a nossa sala de aula, estamos desqualificando a identidade deste indivíduo. Como ela ressalta, "Significa que sua identidade não merece ser representada na dinâmica de sala de aula, que não possui valor, qualidade, voz" (CANEN, op. cit.).

Por este prisma, quando negamos o uso da LIBRAS em sala de aula, ou quando a utilizamos apenas como um meio para alcançar o aprendizado do 
português, ou simplesmente ignoramos o fato de que ela existe, estamos desrespeitando e desqualificando a identidade do aluno surdo. O mesmo ocorre com o português frente ao ensino de uma língua adicional, quando não admitimos seu uso em sala de aula. A privação é a mesma. Como primeira língua ela sempre será a referência para o aprendizado de qualquer outro idioma. Está aí uma das muitas razões para uma perspectiva plurilinguista no ensino de uma língua adicional. Segundo o que nos expõe García (2009) o aprendizado de mais de uma língua "permite que as crianças construam identidades múltiplas, construam habilidades para 'translinguar' ${ }^{\text {iii }}$ e utilizem várias línguas nas maneiras flexíveis do futuro" (GARCÍA, 2009, p.387). Podemos então concluir, de acordo com a colocação da autora que sob a perspectiva plural não há lugar para um idioma dito padrão, por mais que um padrão se sobressaia. A construção e reconstrução de identidades nos levam a necessidade de repensar nossos conceitos, currículos, práticas metodológicas e avaliativas.

\section{A avaliação no contexto da surdez na atualidade: a hora e a vez da interculturalidade e da pluralidade}

Há muito se vem discutindo a avaliação nos mais diversos contextos educacionais; na educação geral, no ensino de línguas, na educação especial, nos contextos de minoria linguística, e obviamente na educação de surdos. Assim como em qualquer outro espaço a avaliação na educação de surdos é concebida através de relações de saber/poder. Até aqui não há nenhuma novidade se comparado ao contexto da educação de um modo geral. "Muitas práticas avaliativas ainda são centradas em práticas hegemônicas que controlam, medem e selecionam" (FIDALGO, 2002; ESTEBAN, 2003). O destaque, porém, que fazem os estudos surdos está na questão de que a avaliação na maioria das escolas brasileiras ainda está centrada na ouvintização do currículo escolar, onde alunos surdos são "alvos de estratégias disciplinadoras que investem constantemente na normalização, na correção, na regulação dos corpos através da vigilância e punição" (CAMILLO, 2009, p.69). Segundo os estudiosos da surdez, como Skliar (2001), Perlin (2003), Cavalcanti e Silva (2007), Gesser (2006), Camillo (2009), Thoma (2009), entre 
outros, nos espaços escolares destinados aos surdos, sejam em escolas de surdos ou situações de inclusão, ainda vigora o processo de normalização e enquadramento da diferença surda aos padrões do modelo ouvinte. Questões sobre currículo não passam das adaptações curriculares feitas no currículo da escola comum, não levando em conta questões mais profundas sobre a diferença. Todos esses impasses normalmente ocorrem dentro do contexto da escola inclusiva, porém o cenário da escola para surdos não é muito diferente. Morais e Lunardi-Lazarin (2009) problematizam o currículo surdo trazendo a seguinte questão:

[...] nesse currículo surdo, também não estaria instituída uma normalidade surda, ou seja, um currículo pensado para o surdo branco, letrado, heterossexual, usuário da língua sinais. Como já foi comentado, o currículo também é produtor de diferenças e identidades, também faz parte de uma rede discursiva permeada por relações de poder - poder esse que penetra, age por meio de técnicas de vigilância cujo efeito será obtido pela sujeição dos corpos. Portanto, tanto a escola comum quanto a escola de surdos possuem dispositivos capazes de colocar esse poder em funcionamento (MORAIS e LUNARDI-LAZARIN, 2009, p.20).

Como levantam as autoras até mesmo em um currículo, pensado para a comunidade surda, mesmo que não intencionalmente, se pode encontrar a busca por uma normalidade surda, ou seja, ainda há a centralização em modelos. A necessidade pela normalização faz com que esses espaços limitem o que é ser surdo. Então, com base nas ideias apresentadas pelas autoras acima e por outros estudiosos da surdez, como Skliar (2001), Perlin (2003), Camillo (2009), etc., pode-se dizer que tal como na escola inclusiva, onde o ouvintismo impera sobre a surdez na busca da normalidade, no contexto da escola para surdos também se busca um 'surdo modelo', quer dizer, aquele que utiliza a LIBRAS padrão, que domina o português-por-escrito, etc. Trata-se de um contexto diferente, porém com o mesmo princípio: o apagamento das diversas identidades que aí se encontram, o descaso pela diferença e pela individualidade do ser humano.

A luta pela diferença e respeito à individualidade é constante. $\mathrm{Na}$ antiguidade as pessoas ditas 'deficientes' eram consideradas inválidas e deveriam ser sacrificadas. "Aristóteles (384-322 a.C.) acreditava que os surdos, por não falarem, não atingiam a consciência humana, portanto não eram 
considerados humanos" (SOUSA, 2008, p. 25). Não se pode desconsiderar o avanço nas conquistas da comunidade surda. A legitimação da língua de sinais, o direito a receber educação através de sua primeira língua, o direito a intérprete de língua de sinais em sala de aula regular e em espaços públicos, a criação de curso de graduação em LIBRAS, entre outros, são alguns dos direitos adquiridos ao longo dessa trajetória de luta.

Nos dias de hoje a abordagem de ensino bilíngue é a mais preconizada para o ensino de surdos, bem como para todos os contextos de ensino de línguas. Autores como García (2009) e Baker et. al. (2012) defendem o aprendizado de toda e qualquer idioma através da perspectiva bilíngue. Sobre um novo angulo e perspectiva de uma educação bilíngue García (2009) comenta que:

No século $X X I$, nossas complexas redes globais comunicativas multilíngues e multimodais frequentemente refletem muito mais do que dois códigos monolíngues separados. Mais do que uma bicicleta com duas rodas balanceadas, a educação bilíngue deve ser mais como um jipe lunar ou um veículo que trafega em qualquer terreno, com diferentes pernas que podem ser estendidas e contraídas de modo a agarrar nos sulcos do solo e crateras da superfície. A comunicação entre seres humanos, especialmente entre crianças e entre crianças e seus professores é cheia de crateras, sulcos e lacunas. E quando essa comunicação ocorre entre crianças falando línguas diferentes, ou entre crianças falando uma língua e o professor outra, essas características são particularmente salientes. Uma bicicleta não funcionaria nesse terreno. $\mathrm{E}$ assim, uma educação bilíngue que valoriza somente partes desconexas e que desvaloriza as partes frequentemente mais soltas, e insiste em uma separação rígida de duas línguas não é o único modo de sucesso para se educar as crianças bilíngues, embora seja ainda uma prática conduzida amplamente (GARCÍA, 2009, p.08).

Esse relato da autora caracteriza adequadamente o dilema pelo o qual passa a educação dos surdos, onde a LIBRAS coexiste com o português, devido às exigências legais. Ela é aceita em sala de aula, porém muitas vezes não é compartida por todos. A utilização da LIBRAS muitas vezes fica reduzida à comunicação do aluno com o intérprete, distanciando o contato do aluno com o professor e seus colegas de sala. O português que deveria ser a segunda língua do surdo, mesmo que somente em sua forma escrita, acaba por parecerIhe estrangeira. Utilizo aqui o termo 'estrangeira' porque 0 isolamento que acomete 0 aluno surdo acaba por tornar a sua $2^{2}$ língua de direito uma língua desconhecida, pertencente ao outro, algo distante de sua realidade. A situação

Pensares em Revista, São Gonçalo-RJ, n.2, p. 109 - 135, jan./jun. 2013 
propícia para que o pluringuismo ocorra, conforme as ideias de García (2009) é uma sala de aula onde os atores desse contexto possam interagir amparados pelos idiomas que circundam por esse espaço, sem travas, sem limites ou preconceitos ou como coloca a autora, "sem crateras, sulcos ou lacunas".

\section{Contextualizando a pesquisa}

Esta pesquisa está sendo desenvolvida sob a perspectiva etnográfica, proporcionando o contato direto da pesquisadora com a situação a ser investigada, o que permitirá a interpretação dos processos que fazem parte da experiência vivida pelos alunos surdos em sua rotina escolar.

Segundo André "a observação participante e as entrevistas aprofundadas são, assim, os meios mais eficazes para que o pesquisador se aproxime dos sistemas de representação, classificação e organização do universo estudado" (ANDRÉ, 2007, p 27). A razão, então, pela escolha do método etnográfico, qualitativo e interpretativo se dá pelo fato de que tal perspectiva permite ao pesquisador vivenciar a riqueza de significados que se encontram no cotidiano escolar dos participantes envolvidos. Sob uma perspectiva êmica, poderemos guiar-nos pelo olhar dos alunos surdos na busca de elementos para a reflexão sobre a relação entre os conhecimentos escolares sistematizados, as práticas avaliativas desenvolvidas na sala de aula de língua adicional e as práticas sociais cotidianas destes indivíduos.

Documentar a prática cotidiana dos envolvidos, levando em conta suas opiniões e pontos de vista, não isenta o pesquisador de expressar seu próprio ponto de vista. Aliás, pode-se dizer que é quase impossível, pois a subjetividade é inerente ao ser humano e ao fazer etnográfico, pois a observação participante caracteriza-se pela convivência do etnógrafo durante um período de tempo no contexto o qual ele quer entender, identificar os significados ali atribuídos, e como coloca Duranti (2000):

A observação de uma comunidade específica não ocorre a partir de um lugar distante e seguro, senão do interior das coisas, isto é, participando em tantos eventos sociais, como seja possível. (DURANTI, 2000, p. 131, grifo do original, tradução minha) $)^{\text {iv }}$ 
Desta forma, a tarefa que cabe ao pesquisador não é a de assumir uma ou outra posição diante do contexto investigado. Ao contrário, este deve possibilitar que os diferentes pontos de vista se revelem, dos pesquisados e do pesquisador, pois não cabe ao linguista aplicado ditar o que é certo ou errado. Seu papel é criar inteligibilidade frente às questões que se revelam no contexto de sua pesquisa, para que assim seus participantes possam repensar suas práticas.

\subsection{O contexto e seus participantes}

A negociação para entrada em campo começou em fevereiro de 2012, através de contato com a Gerência Regional de Educação da grande Florianópolis, que listou dois possíveis colégios para a realização da pesquisa.

O contexto escolhido trata-se de um colégio público, da rede regular de ensino, cujo nome "Colégio Inclusão" será aqui usado de modo fictício para garantir o anonimato da instituição e dos participantes envolvidos. O colégio conta com cinquenta e um alunos surdos, incluídos em turmas regulares, no ensino fundamental (anos finais) e ensino médio. A escolha do colégio Inclusão como contexto para essa pesquisa se deu pelo número de alunos surdos que frequentam as aulas de espanhol. Um total de vinte e dois alunos, número este expressivo se comparado a outras escolas da rede. Outro fator fundamental foi o consentimento da direção da escola e da professora de espanhol. A turma escolhida para a pesquisa, um 60 ano do ensino fundamental (doravante E.F.) é composta de dezoito alunos, sendo que sete deles são surdos, com diferente grau de surdez. O colégio possui em sua grade curricular dois idiomas como disciplinas de línguas estrangeiras ${ }^{v}$, a partir do $6^{\circ}$ ano (E.F.), cabendo ao aluno escolher que língua estrangeira estudará a partir desta etapa.

A professora de espanhol tem o domínio de três idiomas (português, espanhol e LIBRAS), o que, segundo informações recebidas da direção do colégio, contribui para a escolha da maioria dos alunos surdos pelo aprendizado do espanhol como língua adicional. Durante as aulas, o grupo também tem o apoio de uma intérprete de LIBRAS. 
No processo de análise dos dados registrados, encontrei informações que deram origem a algumas categorias que formam uma análise preliminar de minha dissertação de mestrado, a qual apresento nas sessões seguintes.

\section{A rotina de sala de aula e as práticas bi/multilíngues ${ }^{\text {vi }}$ em sala de aula: A participação dos alunos surdos e seu reflexo nas práticas avaliativas}

Foi possível notar, durante as observações, que a presença dos alunos surdos em uma sala ouvinte de língua adicional permite que, além da presença constante do espanhol e do português, também se utilize a LIBRAS. Nessa mescla de idiomas, todos vão desenvolvendo suas práticas de linguagem. Durante a rotina de sala de aula, percebe-se o modo como os alunos ouvintes e surdos lidam com o plurilinguismo. Eles respondem positivamente às práticas multilíngues provocadas especialmente pela professora, naquele cenário como demonstro no exemplo abaixo, com a interação entre Celso, aluno ouvinte e Maria:

No início da aula, Maria, a professora, faz a chamada em português, porém pronunciando os nomes com sotaque espanhol e também em LIBRAS (para os alunos surdos) Celso, aluno ouvinte, pede, em espanhol, para ir ao banheiro:

- ¿Puedo ir al baño, profesora?" (NOTA DE CAMPO, 17/05/2012)

Enquanto a professora utilizava a linguagem buscando fazer com que os alunos ouvintes respondessem em espanhol e os surdos em LIBRAS, Celso realizava a mudança de código, nesse caso do português ao espanhol, para atender suas necessidades momentâneas, o que segundo García (2009) e Baker et. al. (2012) é uma característica central do bilinguismo, quando os aprendizes se utilizam da linguagem aprendida para realizar ações que são de importância pessoal para seus usuários.

O uso de três idiomas concomitante no cotidiano dos atores que ali se encontravam era uma prática já naturalizada naquela sala de aula. Nessa interação entre os alunos e a professora, ao mesmo tempo em que se destacavam as diferenças individuais existentes naquele contexto, se abria um caminho para um objetivo único: aprender um idioma adicional. 
5.1 Os instrumentos de avaliação e a prática pedagógica na sala de aula de Espanhol em um contexto de surdez

O conceito de avaliação diagnóstica estipulado nos documentos da escola sugere uma análise, por parte da professora, do processo de ensino/aprendizagem para verificar as causas do fracasso dos alunos e as possíveis estratégias para a superação das dificuldades encontradas.

Seguindo os mesmos procedimentos metodológicos desde o início das observações, apresento a resposta da professora ao baixo rendimento dos alunos surdos na vinheta abaixo. A professora abre um espaço na sala de aula para comentar os resultados de uma avaliação:

Maria inicia a aula como um conversa séria com os alunos surdos antes de entregar a avaliação corrigida (ditado de nomes de animais). Utilizando-se da LIBRAS ela fala da necessidade dos alunos surdos estudarem para as avaliações. Levanta a questão do comodismo dos surdos, que por sua condição de surdos acham que a rotina escolar será facilitada. Deixa claro que eles são iguais aos demais, e serão tratados como tal. Devem estudar para aprender espanhol, senão continuarão tirando nota baixa. (NOTA DE CAMPO, 10/07/2012)

A fala de Maria retrata uma ideologia subjacente, muitas vezes naturalizada e legitimada em contextos escolares. Essa ideologia homogeneizante busca a padronização, tão desejada pelo discurso hegemônico. Os surdos, quando não excluídos por sua diferença, são silenciados por uma estrutura escolar, de modo que a inclusão só acontece, efetivamente, no papel. Práticas desconectadas da realidade deste grupo produzem o discurso da igualdade e buscam o enquadramento do aluno surdo na dita 'normalidade' (CAVALCANTI e SILVA, 2007).

Em uma sociedade extremamente desigual, a luta por igualdade dos grupos minoritarizados não é novidade para ninguém, porém a igualdade tão almejada não pode ser traduzida pela busca da padronização. A igualdade que busca a comunidade surda é o direito de receber sua instrução com as adaptações necessárias, como indicam os documentos oficias do país/estado (PCN, Orientações Curriculares, Política de Educação de Surdos no Estado de Santa Catarina) para que de fato exista a possibilidade do aprendizado. É o direito de ser diferente. Segundo Santos (1999) "temos o direito de ser 
diferentes, quando a igualdade põe em risco nossa identidade, e temos que lutar por igualdade quando a diferença acarrete inferioridade." (SANTOS apud RIBETTO et. al., 2003:103).

Por detrás do "comodismo" podem estar imbricados diversos motivos para o baixo rendimento apresentado pelos alunos surdos que vão além das paredes da sala de aula e que ultrapassam a passividade. A realização de práticas avaliativas homogeneizantes não acolhe a diversidade existente na sala aula, seja o aluno 'especial' ou não. Segundo Esteban (2003) "a avaliação que impede a expressão de determinadas vozes é uma prática de exclusão na medida em que vai selecionando o que pode ser aceito na escola" (2003, p.16). A necessidade de repensar a prática avaliativa é fato inegável para que se possa colaborar com a realidade da inclusão na escola e assim acompanhar o que autora define como "um paradigma emergente que fala do caos, da desordem, da multiplicidade, do híbrido, do deslocamento, da inconstância, da negociação, da tradução, de fluidez, de margens, de inconsistência, de movimento" (ESTEBAN, op. cit., p.31).

5.2 "Professora só passa a prova pro aluno": a necessidade de instrumentos que dêem voz e visibilidade ao aluno surdo

Considerando-se que esta se trata de uma pesquisa de cunho etnográfico, de caráter êmico, apresento nessa seção uma pequena mostra da visão dos alunos surdos quanto à prática avaliativa utilizada na sala de aula de espanhol, como língua adicional.

Em uma entrevista com o grupo de alunos, pergunto-lhes como gostariam de ser avaliados na aula de espanhol e peço-Ihes que escrevam sua opinião para mim. Abaixo, apresento a resposta de Juliana, uma aluna surda:

Professora fala pro aluno amanhã tem prova. Eu chego em casa, estudo pra prova de amanhã. Professora só passa a prova pro aluno. Não é só prova, precisa o trabalho também.

Quero o trabalho mais fácil, $m+$ bem! (MENSAGEM ESCRITA, Juliana, 13/09/2012)

A perspectiva da aluna por outros tipos de trabalho parece evidenciar 0 desejo de novos instrumentos, o que talvez possa lhe proporcionar a 
oportunidade de demonstrar habilidades até então desconhecidas pela professora. Segundo Schlatter e Garcez (2012):

Talvez pela falta de oportunidade para refletir sobre práticas alternativas, [...] professores optam por fazer avaliação "para constar", atendendo às exigências administrativas de produzir notas, conceitos e pareceres, mas deixando assim de reconhecer que a avaliação pode ser uma experiência de aprendizagem para todos os envolvidos na educação escolar (SCHLATTER e GARCEZ, 2012, p.155)

A necessidade de responder as demandas que englobam o processo avaliativo (cumprir planejamento, fechar notas, fazer relatórios, dar respostas aos alunos, escola e pais) acaba afastando o professor do verdadeiro sentido de avaliar que é o compartilhamento das práticas que acontecem na sala de aula, o aprendizado mútuo e as relações que ali se constroem. No ato de medir, avaliar e hierarquizar muitos dos instrumentos avaliativos servem apenas para o distanciamento dos sujeitos envolvidos nesse processo, configurando a visão hegemônica, onde a função do professor é a de transmitir conhecimento e a do aluno, recebê-lo e devolvê-lo através de testes que medem e estipulam um valor ao indivíduo. Neste paradigma de avaliação o aluno perde o que há de melhor no aprendizado de uma língua adicional, qual seja, apropriar-se dela para seu próprio benefício, usá-la para participar do mundo que o rodeia.

Na próxima vinheta, registro a opinião de uma aluna surda, pronunciada através da LIBRAS e traduzida pela intérprete, sobre uma avaliação diferenciada feita em sala de aula.

Laura (interpretada por Alice): - Quinta-feira teve prova.

Professora Maria: - Foi o ditado. Foi feito ditado.

Eliane: - O que que houve?

Laura (interpretada por Alice): - Foi bom o ditado! Gostei de fazer o ditado! Foi fácil! Porque tinha desenho, tinha LIBRAS. Então ficou mais fácil responder em espanhol. (ENTREVISTA COLETIVA, 12/09/2012, grifo meu)

Esta prova foi de particular importância para o grupo de alunos surdos do $6^{\circ}$ ano. Pela primeira vez, desde que havia iniciado as observações, em 17/05/2012, presenciei a realização de uma atividade avaliativa direcionada especialmente para os alunos surdos, respeitando assim suas peculiaridades,

Pensares em Revista, São Gonçalo-RJ, n.2, p. 109 - 135, jan./jun. 2013 
como o uso da LIBRAS, e, mais que isso, respeitando seu direito de uma educação bilíngue. Laura diz em seu comentário que gostou de fazer a prova, que "foi fácil" e relaciona essa facilidade com a utilização dos sinais em LIBRAS através de desenhos.

A atitude da professora, mais uma vez, positiva, proporcionou aos alunos surdos a chance de demonstrarem seu desempenho através de um instrumento avaliativo coerente com a realidade de seus alunos, além de cumprir através dessa mudança de atitude duas de muitas diretrizes da política de educação dos surdos: avaliação adaptada e o ensino em 1a língua. Os documentos oficiais que orientam a educação brasileira sugerem em seu texto que as avaliações para os alunos com necessidades educacionais sejam adaptadas assim como todo o currículo da escola. Aos alunos surdos é garantido o ensino através de sua primeira língua. Essas diretrizes estão presentes na Declaração de Salamanca (1996), na LDB (1996), nos PCN (1998), na política de educação de surdos de estado de Santa Catarina (2004) e nas Orientações Curriculares para pessoas surdas do Estado de São Paulo (2008). O exemplo da prova, embora uma atitude ainda isolada, fez com que valesse, naquele momento, nessa sala de aula, os direitos dos alunos surdos que compõem esse cenário educacional. O bilinguismo é direito adquirido pela comunidade surda, porém são raros os casos em que este direito é contemplado nas práticas avaliativas. Segundo García (2009):

[...] enquanto alunos na educação bilíngue aprendem a agir como profissionais e indivíduos bilíngues, a avaliação na maioria das vezes ignora o seu bilinguismo e avalia as suas habilidades e conhecimentos somente como se eles fosse monolíngues nas línguas de domínio e de poder (GARCIA, 2009, p.367).

Segundo Machado (2008) a utilização da LIBRAS em todo o contexto social, no qual a comunidade surda está inserida não é mera convenção. É a garantia de que esses indivíduos possam participar do mundo que os rodeia e das discussões que nele surgem, com igualdade e condições como qualquer outro ser humano, porém reconhecendo suas peculiaridades. Sendo assim a instituição escola não pode negar-Ihe este direito. A presença de professores bilíngues e intérpretes neste contexto é um dos vários recursos para a concretização do ensino desse grupo. Quando o aluno é privado de uma 
avaliação coerente com esse princípio, é também negado a ele um dos direitos humanos mais cobiçados, o direito de igualdade. Essa igualdade é definida aqui como o direito de ser diferente e não ser discriminado, tampouco 'normalizado' e como o direito de poder expressar-se através de um dos seus bens mais precioso: a linguagem. No caso dos alunos surdos pode-se dizer "as linguagens", pois, teoricamente, este é um grupo contemplado com dois idiomas: aquele que o identifica como parte de um grupo com características específicas, os surdos, consistindo em usuário da LIBRAS, e outro que o caracteriza como cidadão brasileiro, portanto falante da língua portuguesa. Então é inegável que o aluno surdo é um indivíduo bilíngue, e por sê-lo tem o direito à educação bilíngue e de práticas avaliativas que contemplem esse bilinguismo.

\section{Para onde apontam os dados}

Este é um trabalho ainda em andamento e, por se tratar de uma pesquisa de cunho etnográfico, à medida que os registros de dados vão sendo gerados, novos conceitos poderão surgir, exigindo novas leituras e novas análises. Sendo assim, pretendo, no decorrer dessa pesquisa de mestrado, aprofundar as discussões sobre o sentido das práticas avaliativas nas aulas de espanhol no contexto de surdez; porém, até este momento, o que podemos perceber é que o conceito de proficiência em espanhol nesse contexto não parece estar claramente definido. Além disso, os instrumentos e modelos de avaliação utilizados divergem das práticas de linguagem dos alunos surdos, fato que nos leva a uma questão a ser refletida: que instrumentos então, contemplariam suas realidades?

\section{Referências bibliográficas}

ANDRÉ, M. E.D. A. de. Etnografia da Prática Escolar, 18ª̣. edição. Campinas,SP: Papirus, 2011.

BAKER, C.; JONES, B.; LEWIS, G. Translanguagin: origins and development from school to street and beyond, School of Education University, ESRC Bilingualism Centre at Bangor University, 2012. Disponível em: 
http://journalseeker.researchbib.com/?action=viewJournalDetails\&issn=138036 11\&uid=re261c. Acesso em 22 de out. de 2012.

BIZARRO, R.; BRAGA, F. Educação intercultural, competência plurilíngüe e competência pluricultural: Novos desafios para formação de professores de línguas estrangeiras, Universidade do Porto, 2001, disponível em: ler.letras.up.pt/uploads/ficheiros/4373.pdf. Acesso em: 15 de jul.de 2012.

BRASIL, Lei de Diretrizes e Bases da Educação (LDB) No. 9.394. Disponível em: http://www.planalto.gov.br/ccivil 03/leis/L9394.htm. Acesso em 21 de out. de 2012.

Parâmetros Curriculares Nacionais, 5a. a 8 a . séries, Língua Estrangeira, Brasília. 1998.

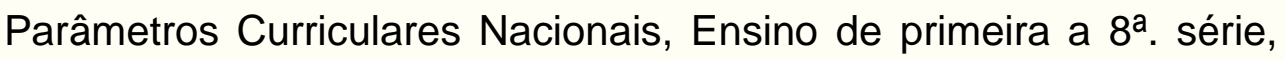
Adaptações Curriculares: estratégias para a educação de alunos com necessidades educacionais especiais, Brasília. 1998.

Parâmetros Curriculares Nacionais, Pluralidade Cultural, Educação Sexual, Brasília. 1997.

CAMILLO, C. R. M. Avaliação como dispositivo pedagógico: narrativas de professores surdos no contexto das práticas pedagógicas. In: KLEIN, M. (Orgs.) Currículo \& Avaliação, Santa Cruz do Sul: EDUNISC, 2009.

CANEN, A. Multiculturalismo e Alfabetização: algumas reflexões. In: Contrapontos, ano 2, no.4, Itajaí, jan/abr/2002.

CATANI, D. B.; GALLEGO, R. de C. Avaliação. São Paulo, SP: UNESP (FEU), 2009.

CAVALCANTI M. C.; SILVA I. R. "Já que ele não fala, podia ao menos escrever": o grafocentrismo naturalizado que insiste em normalizar o surdo, In: KLEIMAN, Angela B. e CAVALCANTI (Orgs) - Linguística Aplicada: suas faces e interfaces. Campinas, SP: Mercado de Letras, 2007.

CAVALCANTI, M C. Estudos sobre Educação Bilíngue e Escolarização em Contextos de Minorias Linguísticas no Brasil. In: D.E.L.T.A., Vol. 15, no. Especial, 1999 (385-417).

CLEMENTE, A. Pedagogía crítica en el aprendizaje de lenguas en México. In: Imaginales 8, México, jul./dez. 2009.

COX, M. I. P.; ASSIS-PETERSON, A. A. Critical Pedagogy in ELT: Images of Brazilian Teachers of English. In: TESOL QUARTERLY, vol. 33, no. 3, 1999.

DURANTI, A. Antropología Linguística. Madrid: Cambridge University Press, 2000. 
ESTEBAN, M. T. (Org.) Escola, Currículo e Avaliação, São Paulo: Cortez, 2003.

FIDALGO, S. S. Avaliação de Aprendizagem: Ferramenta para formação de agentes críticos, Dissertação de Mestrado, São Paulo, LAEL, PUC, 2002.

FREIRE, P. Pedagogia do Oprimido, Rio de Janeiro: editora Paz e Terra, 50 ed., rev. e atual, 2011.

GARCíA, O. Bilingual Education in the 21st Century: a global perspective. Oxford: Wiley-Blackwell, 2009.

GESSER, A. LIBRAS? Que língua é essa: crenças e preconceitos em torno da língua de sinais e da realidade surda, São Paulo: Parábola, 2009.

"Um olho no professor surdo e outro na caneta": ouvintes aprendendo a Língua de Sinais Brasileira, Tese de Doutorado, UNICAMP, Instituto de Estudos da Linguagem, Campinas, 2006.

GRANNIER, D. M. A jornada linguística do surdo da creche a universidade. In: KLEIMAN, Angela B.; CAVALCANTI (Org.) Linguística Aplicada: suas faces e interfaces. Campinas, SP: Mercado de Letras, 2007.

LUCENA, M. I. P. Razões e realidades no modo como as professoras de inglês como língua estrangeira de escola pública avaliam seu trabalho. 2006. Tese (Doutorado em Letras). Porto Alegre: Universidade Federal do Rio Grande do Sul, 2006.

Avaliação e o papel educacional do ensino de línguas estrangeiras: questões teóricas e metodológicas. In: Revista Sobretudo, Colégio de Aplicação da UFSC, 2009.

Avaliação no ensino de línguas, formação de professores e sociedade contemporânea. Anais eletrônicos, IV Congresso Brasileiro de Linguística Aplicada, ALAB, 2011.

O papel da pesquisa de cunho etnográfico na discussão das políticas educacionais de línguas. In: FRITZEN, M. P.; LUCENA, M. I. P. (Orgs) $O$ olhar da etnografia em contextos educacionais: Interpretando práticas de linguagem. Blumenau: Edifurb, 2012.

MACHADO, P. C. A política educacional de integração/inclusão, um olhar do egresso surdo, Florianópolis: Editora da UFSC, 2008.

MAHER, T. M. Do casulo ao movimento: a suspensão das certezas na educação bilíngue e intercultural. In.: CAVALCANTI, M. C.; BORTONIRICARDO, S. M. (org.). Transculturalidade, linguagem e educação. Campinas, SP: Mercado de Letras, 2007. 
A educação do Entorno para a Interculturalidade e o Plurilinguismo. In: KLEIMAN, A. B.; CAVALCATI, M. C. (Orgs.) Linguística Aplicada: suas faces e interfaces. Campinas, SP: Mercado de Letras, 2007.

MIRANDA, S. F. Educação Multicultural e Formação de Professores, Dissertação de Mestrado em Relações Interculturais, Porto: Universidade Aberta, 2001.

MOITA LOPES, Luiz Paulo da. Oficina de lingüística aplicada: A natureza social e educacional dos processos de ensino/aprendizagem de línguas. Campinas: Mercado de Letras, 1996.

Parábola Editorial, 2006.

Por uma linguística aplicada Indisciplinar. São Paulo:

MORAIS, M. Z. de; LUNARDI-LAZZARIN, M. L. Pedagogia e diferença: capituras e resistências. In: KLEIN, M. (Orgs.) Currículo \& Avaliação. Santa Cruz do Sul: EDUNISC, 2009.

MOURA, S. A. Com quantas línguas se faz um país? Concepções e práticas de ensino em uma sala de aula bilíngue, Dissertação de Mestrado, Faculdade de Educação da Universidade de São Paulo, 2009.

NORTON, B.; TOOHEY, K. (Ed.) Critical pedagogies and language learning, Cambridge, Cambridge University Press, 2009.

PENNYCOOK, A. A Linguística Aplicada dos anos 90: em defesa de uma abordagem crítica. Trad. de Denise B. B. Braga e Maria C. dos S. Fraga. In.: SIGNORINI, I.; CAVALCANTI, M. C. (Orgs) Linguística Aplicada e Transdisciplinaridade. Campinas, SP: Mercado de Letras, 2007.

PERLIN, G. T. T. O ser e o estar sendo surdos: alteridade, diferença e identidade, Tese de Doutorado, UFRGS, Porto Alegre, 2003.

PORTUGAL. Quadro Europeu Comum de Referência para as línguas aprendizagem, ensino, avaliação, Porto, Portugal: Asa Editores II, 2001.

QUADROS, R. M. de; PERLIN, G. T. T. Educação de Surdos na Escola Inclusiva? In: Revista Espaço: informe técnico científico do INES, Rio de Janeiro, 1997, p.35-40.

QUADROS, R. M. de. Educação de Surdos: aquisição da linguagem, Porto Alegre: Artes Médicas, 1997.

QUADROS, R. M. de. Políticas lingüísticas e educação de surdos. In: V Congresso. Internacional e XI Seminário Nacional do INES, 2006, Rio de Janeiro. 
RIBETTO, A.; VASCONCELOS, G. A. N.; SGARBI, P.; FILÉ, W. Conversas sobre avaliação e comunicação. In: ESTEBAN, Maria Teresa (Org.) Escola, Currículo e Avaliação. São Paulo: Cortez, 2003.

RAJAGOPALAN, K. Por uma linguística crítica: linguagem, identidade e a questão ética, Párabola, São Paulo, 2003.

SÁ, N. R. L. de. A questão da Educação de Surdos. In: SÁ, N. R. L. de. Cultura, poder e educação de Surdos. São Paulo: Ed. Paulinas, 2006.

Educação de Surdos: a caminho do bilinguismo. Niterói, EduFF, 1999.

SANTA CATARINA. Política de Educação de Surdos de Santa Catarina, Secretaria da Educação e Inovação, Santa Catarina, 2004.

SCARAMUCCI, M. V. R. Proficiência em LE: Considerações terminológicas e conceituais. In: Trabalhos em Linguística Aplicada (36): 11-12, Jul./Dez., 2000, Departamento de Linguística Aplicada, IEL, Unicamp.

Validade e consequências sociais das avaliações em contextos de ensino de línguas. In:, Linguarum Arena, Vol.2, ano 2011. 103-120, Campinas, SP, 2011.

SCHLATTER, M.; GARCEZ, P. de M. Línguas adicionais (espanhol e inglês). In.: Referenciais Curriculares do Estado do Rio Grande do Sul: Linguagens, Códigos e suas Tecnologias. Porto Alegre: SE/DP, v.1, p. 127-172, 2009.

SKLIAR, C. A Surdez: um olhar sobre as diferenças. 2. ed. Porto Alegre: Mediação, 2001.

SCHLATTER, M.; ALMEIDA, A. do N.; FORTES, M. S.; SCHOFFEN, J. R. Avaliação de desempenho e os conceitos de validade, confiabilidade e efeito retroativo. In: FLORES, V. do N.; NAUJORKS, J. da C.; REBELLO, L. S.; SILVA, D. S. (orgs.). A redação no contexto do vestibular 2005: a avaliação em perspectiva. Porto Alegre: Editora da UFRGS, 2005.

SOUSA, A., N. de. Surdos Brasileiros escrevendo em Inglês: uma experiência como o ensino comunicativo de línguas, Dissertação de Mestrado, Universidade Federal do Ceará, Fortaleza, 2008.

THOMA, A. da S. Identidades e diferença surda constituídas pela avaliação. In: KLEIN, M. (Orgs.) Currículo \& Avaliação. Santa Cruz do Sul: EDUNISC, 2009.

UNESCO. Declaração de Salamanca: Sobre princípios, políticas e práticas na área das necessidades educativas especiais, 1994. Disponível em: http://portal.mec.gov.br/seesp/

arquivos/pdf/salamanca.pdf. Acesso em 23 de out. de 2012.

ZABALA, A.. A prática educativa: como ensinar, Porto Alegre, Artmed, 1998. 
' Termo cunhado por Cavalcanti (1999) para referir-se as maiorias linguísticas que são invisibilizadas e tratadas como minoria linguística, como é o caso dos alunos que compõem a grande massa populacional nas escolas públicas.

ii O término educação intercultural substitui a expressão educação multicultural. Maher (2003) considera que o "termo interculturalidade traduz melhor a essência daquilo que tanto chama nossa atenção e no preocupa contemporaneamente. Além de muito menos polissêmico e menos saturado, menos banalizado do que multiculturalismo, 0 termo interculturalidade evoca, mais prontamente, a relação entre as culturas, que é o que de fato importa". (MAHER, 2007 in: KLEIMAN e CAVALCANTI, 2007, p. 265)

iii A autora define translanguaging como a habilidade do falante bilíngue permutar de um código a outro na sua necessidade de fazer sentido em seu próprio mundo, que é envolto por várias línguas. A habilidade de mudar de um idioma a outro sob esta perspectiva vai além do conceito de code-switching. Não se trata de mera alternância de código, pois o contexto discursivo é primordial. Ela considera como uma estratégia que bilíngues usam para fazer sentido, moldar suas experiências, obter a compreensão e conhecimento, e dar sentido a seus mundos bilíngues através do uso diário de duas ou mais línguas. (GARCÍA, 2009). Alguns autores pesquisadores vêm traduzindo o termo translanguaging como 'translinguagem' (ver Maroto, 2012).

iv Tradução original: "La observación de una comunidad específica no se lleva a cabo desde un lugar distante e seguro, sino desde el interior de las cosas, esto es, participando en tantos eventos sociales, como sea posible". (Tradução espanhola de Pedro Tena)

${ }^{\vee}$ Nomenclatura utilizada pelo colégio em seus documentos oficiais.

vi Utilizarei durante a análise dos dados a expressão "bi/multilíngüe" para identificar ao uso de duas ou mais línguas pelos participantes do contexto. Tal escolha se dá pelo fato que as prática dialógicas expressas como exemplos nessa pesquisa, dependendo de seus participantes, às vezes são bilíngues e em outras multilíngues.

Artigo recebido em: 31 de março de 2013

Artigo aprovado em: 8 de junho de 2013

\section{Sobre a autora:}

Mestranda em Linguística na Universidade Federal de Santa Catarina. 
